\title{
Teachers' Perceptions of the Use of Blended Learning for Instructional Delivery and Student Production in K-12 Classrooms
}

\author{
Janet Turner \\ Department of Educational Leadership, Samford University \\ 800 Lakeshore Drive, Birmingham, Alabama \\ E-mail: jturner5@samford.edu

\section{Wanda Young-Lowe} \\ Department of Educational Leadership, Samford University \\ 800 Lakeshore Drive, Birmingham, Alabama \\ E-mail: wyoung1@samford.edu \\ Jodi Newton (Corresponding author) \\ Department of Educational Leadership, Samford University \\ 800 Lakeshore Drive, Birmingham, Alabama \\ Tel: 1-205-726-4240 E-mail: jbnewton@samford.edu
}

Received: March 20, 2018 Accepted: April 5, 2018 Published: May 3, 2018

doi:10.5296/ijld.v8i2.12863 URL: https://doi.org/10.5296/ijld.v8i2.12863

\begin{abstract}
This study seeks to determine teachers' perceptions of the benefits of blended learning by grade span groupings: elementary, middle, and high school teachers and to examine teachers' perceptions of their use of blended learning for instructional delivery and student production. The rapid growth of blending learning has created need for investigations into teachers' perceptions of the benefit of blended learning. Data were gathered using quantitative research techniques with the use of a Likert scale on a three-part survey that analyzed a total of 460
\end{abstract}


public school teachers' perceptions regarding blended learning as an instructional delivery approach in the classroom. The researchers designed the Turner \& Young Technology Teacher Survey to study how teachers perceive blended learning in the classroom controlling for grade span groupings. The findings of this study indicated differences in teachers' attitudes about the benefit of blended learning by grade span groups, particularly as it relates to instructional strategy. In addition, the results of this study indicate that as teachers recognized the benefits of blended learning, teachers also increased their use of blended learning for instructional delivery and for student production. This research adds to a small literature base examining the use of blended learning by grade span groupings.

This study seeks to determine teachers' perceptions of the benefits of blended learning by grade span groupings: elementary, middle, and high school teachers and to examine teachers' perceptions of their use of blended learning for instructional delivery and student production. The rapid growth of blending learning has created need for investigations into teachers' perceptions of the benefit of blended learning. Data were gathered using quantitative research techniques with the use of a Likert scale on a three-part survey that analyzed a total of 460 public school teachers' perceptions regarding blended learning as an instructional delivery approach in the classroom. The researchers designed the Turner \& Young Technology Teacher Survey to study how teachers perceive blended learning in the classroom controlling for grade

Keywords: Blended learning, instruction delivery, student production

\section{Introduction}

The National Education Technology Plan, released by the U.S. Department of Education in 2016, called for transforming American education to include personalized learning experiences and technology as a platform for delivery (National Education Technology Plan, 2016). Blended learning is growing rapidly, and continued expansion is expected with more than half of high school students predicted to participate in some type of asynchronous course or study by 2019 (Christensen, Horn, \& Staker, 2013). By examining teachers' perceptions of blended learning in K-12 classroom settings, this study provided information regarding teacher perceptions and use of blended learning as well as the instructional strategies believed to best improve student achievement.

\section{Relevant Scholarship}

The effective integration of technology into education has been throttled by the advancement of a variety of digital devices available, such as laptops, iPhones, PDAs, or equipment that can be used with computers. Although disparities in technology are evident with "some groups having persistently lower rates of internet adoption, the vast majority of Americans are online" (Anderson \& Perrin, 2016, para. 7). Blended learning is possibly "the fastest-growing segment in online learning" (Stephens, 2016, para. 1.). An online learning survey reported that "blended learning was expanding globally at $46 \%$ or more per year" (Hillard, 2015, p. 179). According to Wang, Han, and Yang (2015) "online learning was one of the fastest growing trends in educational uses of technology" (p. 12). "Blended learning emerged as one of the most popular 
pedagogical concepts at the beginning of 2000" (Guzer \& Caner, 2014, p. 4596). The shift of blended learning into the traditional classroom, and greater acceptance and availability of online courses, has allowed blended learning to offer the best approach to combining the two modes. Blended learning has offered a variety of digital learning experiences in K-12 face-to-face, brick and mortar schools. Technology use is gaining momentum in public schools across the country at a rapid pace, highlighting the need for more research on understanding blending learning in K-12 education. Therefore, the relevant and practical nature of blended learning in reference to technological applications necessitates evidence-based proof of its educational value (Kazu \& Demirkol, 2014).

The Metropolitan Educational Research Consortium completed a thorough review of literature utilizing printed material and databases from Virginia Commonwealth University Cabell Library and found that "the number of journal articles that directly addressed online or blended learning in K-12 settings was astonishingly low" (Kassner, 2013, p. 2). Picciano, Dziuban, \& Graham, (2015) reported, "studies of blended learning in postsecondary environments have a longer history than studies conducted in the K-12 settings" (p. 287). Nadelson, Bennett, Gwilliam, Howlett , Oswald \& Sand, (2013) argued "enhancing teachers' capacity to effectively use instructional technology begins with assessing their perceptions, experiences, and vision for using technology in the classroom and analyzing the interactions between these variables" (p. 80).

Blended learning schools could predictably become "the dominant model of schooling in the United States in the future" (Christensen, et al., 2013, p. 25). Jeffrey, Milne, and Suddaby (2014) "implied that blended learning would not fulfill its promise unless teachers were encouraged to re-think and redesign their courses that afforded students more and different learning experiences than those offered by either online or classroom alone" (p. 121). Since the instructional platform required changing skillsets and attitudes, administrators and faculty could best make decisions about web-based asynchronous learning strategies when they understood the perceived benefits and challenges to incorporating blended learning in K-12 classrooms. Teachers who did not understand or see the benefits of blended learning were less likely to fully integrate an effective blended learning environment where students were engaged in critical and creative thinking strategies.

Educational leaders have acknowledged the potential of using blended learning models to revolutionize the educational system and create higher levels of thinking through the use of proficient learning standards (Powell, Watson, Staley, Horn, Fetzer, \&Verma (2015). Blended instruction, especially those models reinforced by differentiated resources, allowed educators to connect the "right student with the right content at the right time," thereby creating a unique form of schooling that produced the best educational setting for both the instructor and the learner (Powell et al., 2015, p. 6). According to Kazu \& Demirkol (2014), students who used a blended learning model that incorporated both online and traditional face-to-face instruction improved academic success due to the accessibility of universal information via technological resources and the availability of cyber-based engagement. Blended instructional models placed 
the student at the center of the educational process by using technology to create a personalized pathway of learning that produced more engaged, proficient, and beneficial outcomes (Powell et al., 2015).

The existing research on blended learning has not adequately articulated the specific factors that influenced faculty decisions to incorporate blended learning and the changes that needed to evolve. Whiteside (2015) cautioned that when researching the element of blended learning instruction, examining the relationship between face-to-face instruction and online learning was imperative. "Investigations into blended learning continue to be fragmented and many important issues remain unexplored" (Wang et al, 2015, p. 380).

\section{Research Purpose}

Considering the need for investigations into blended learning, the researchers sought to determine teachers' perceptions of the benefit and appropriateness of blended learning. Researchers investigated the following five research questions: (1) Was there a difference in teachers' perceptions of the use of blended learning by elementary, middle, and high school teachers? (2) Was there a difference in teachers' perceptions of their use of blended learning for instructional delivery by elementary, middle, and high school teachers? (3) Was there a difference in teachers' perceptions of their use of blended learning for student production by elementary, middle, and high school teachers? (4) Was there a relationship between teachers' perceptions of the benefits of blended learning and their use of blended learning for instructional delivery? (5) Was there a relationship between teachers' perceptions of the benefits of blended learning and their use of blended learning for student production. The researchers asked a sixth question for information related to teacher knowledge of specific models of blended learning but did not provide a statistical application related to the question.

\section{Method}

This quantitative research was conducted utilizing a survey design. The study assessed teachers' perceptions of blended learning among elementary, middle, and high school levels. This was accomplished using a descriptive rating, Likert-scale survey of K-12 certificated teachers in a large county school system in a southeastern state. The survey design was chosen for this study because it allowed the researchers to collect data from all certified classroom teachers in a large county school system. The researchers designed the Turner \& Young Technology Teacher Survey to study how teachers perceive blended learning in the classroom controlling for grade span groupings. The instrument was tested for validity and reliability in a field test. The survey was electronically disseminated through email. Participants were voluntary and individual results were anonymous. The district superintendent granted permission to invite teachers to participate in the survey.

\subsection{Participants}

The population for this study was drawn from approximately 460, K-12 teachers in a public-school system located in central Alabama. This southeastern school district served approximately 7,700 students in 17 schools, which included seven elementary schools, three middle schools, six high schools, and one K-12 school. The elementary and middle schools and 
one high school in the study have over $80 \%$ poverty, are Title I schools, and receive additional funding to supplement school improvement efforts. Members of this population were identified as: K-5, 6-8, \& 9-12 certified, regular classroom teachers.

\subsection{Design}

Researchers used two types of statistical tests to explore the study. The first three proposals were assessed with the use of an ANOVA one-way statistical test. The fourth and fifth proposals were assessed with the use of a Pearson- $r$ statistical test. This study consisted of five statistical tests used to assess one survey.

To measure teachers' perceptions of the implementation of blended learning instruction, participants responded to the Turner \& Young Teacher Technology Survey (TYTTS) designed by the researchers. The survey was administered using Qualtrics software to 460 certified classroom teachers through their school district email addresses. The researchers sent additional follow-up emails, asking non-respondents for their assistance in completing the survey, and the study yielded a response rate of $49.6 \%$.

Table 1. Response rate for survey by grade span grouping

\begin{tabular}{lll}
\hline Grade Span Grouping & Respondents & Response Rate \\
\hline Elementary & 123 & $53.95 \%$ \\
Middle & 29 & $12.72 \%$ \\
High & 76 & $33.33 \%$ \\
\hline
\end{tabular}

Table 1 reports the response rates for the survey for each grade span.

\subsection{Data Analysis Results}

Hypothesis 1: There is no statistically significant difference in teachers' perceptions of blended learning by elementary, middle, and high school. The null hypothesis was not supported by findings and was rejected. Elementary school teachers scored significantly higher, having more positive perceptions of blended learning than teachers in high school followed by scores from middle school teachers.

Hypothesis 2: There is no statistically significant difference in teacher's perceptions of their use of blended learning for instructional delivery by elementary, middle, and high school. The null hypothesis was not supported by the findings and was rejected. Elementary school teachers scored significantly higher, having greater use for instructional delivery than teachers in high school followed by scores from middle school teachers.

Hypothesis 3: There is no statistically significant difference in teachers' perceptions of their use of blended learning for student production by elementary, middle, and high school teachers. The one-way ANOVA did not reveal a statistically significant main effect among the three 


\section{Macrothink}

mean scores. Therefore, the null hypothesis was not rejected. The teachers showed no significant difference by grade span for use of blended learning for student production.

Hypothesis 4: There is no statistically significant relationship in teachers' perceptions of the benefits of blended learning and their use of blended learning for instructional delivery? There was a significant positive correlation between teachers' perceptions of the benefits of blended learning and their use of blended learning for instructional delivery, $\mathrm{r}(226)=.72, \mathrm{p}<.001$. As teachers perceive a high level of benefits they also report a high level of the use of blended learning for instructional delivery. Therefore, the null hypothesis was rejected.

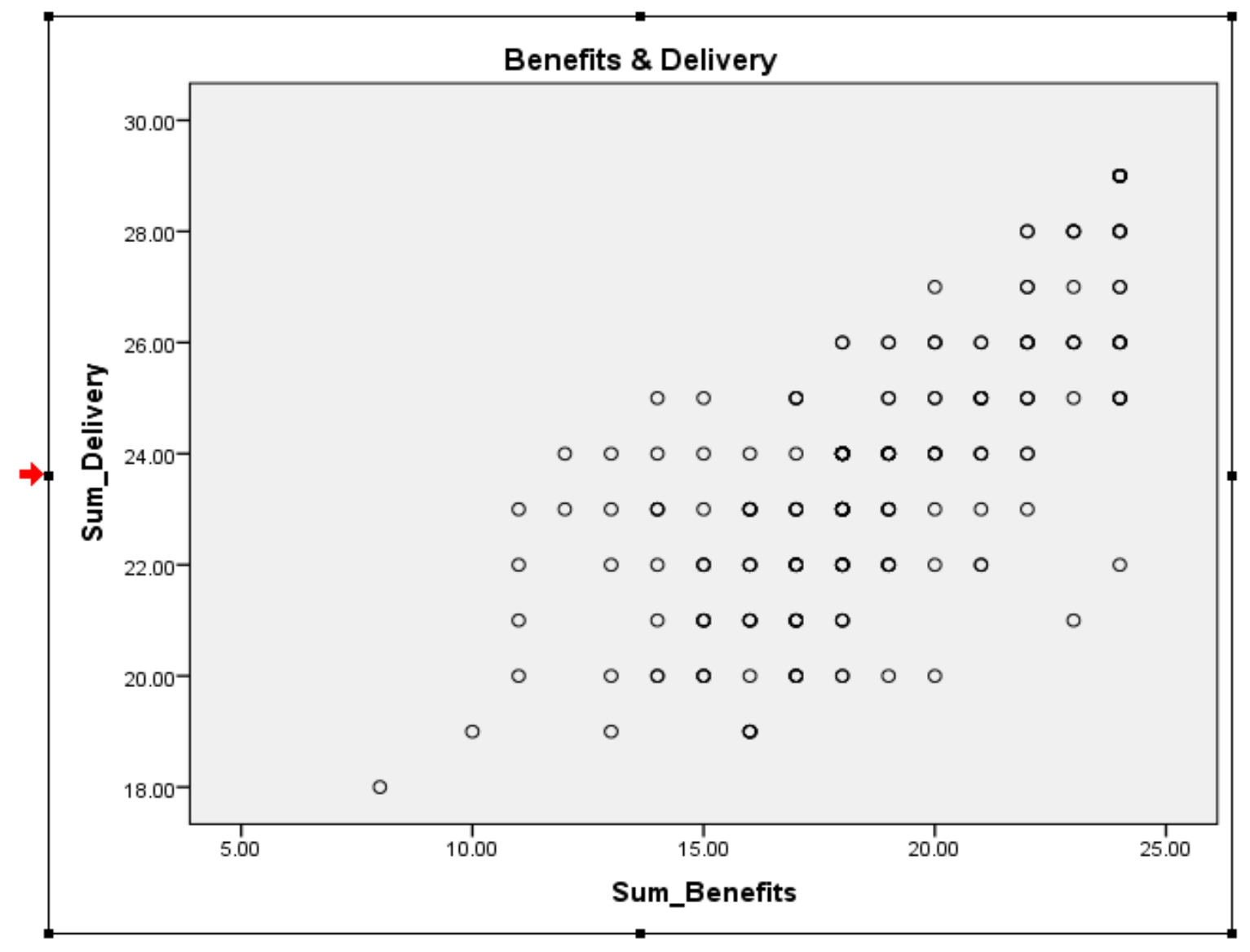

Figure 1. Scatter Plot of Positive Correlation

Figure 1 displays as teachers increased their agreement with the benefits of blended learning, they also reported a high level of the use of blended learning for instructional delivery.

Hypothesis 5: There is no statistically significant relationship in teachers' perceptions of the benefits of blended learning and their use of blended learning for student production. There was a significant positive correlation between the teachers' perceptions of the benefits of blended learning and their use of blended learning for student production, $r((226)=.70, p$ $<.001$. As teachers perceive a high level of benefits they also report a high level of the use of blended learning for student production. Therefore, the null hypothesis was rejected. 


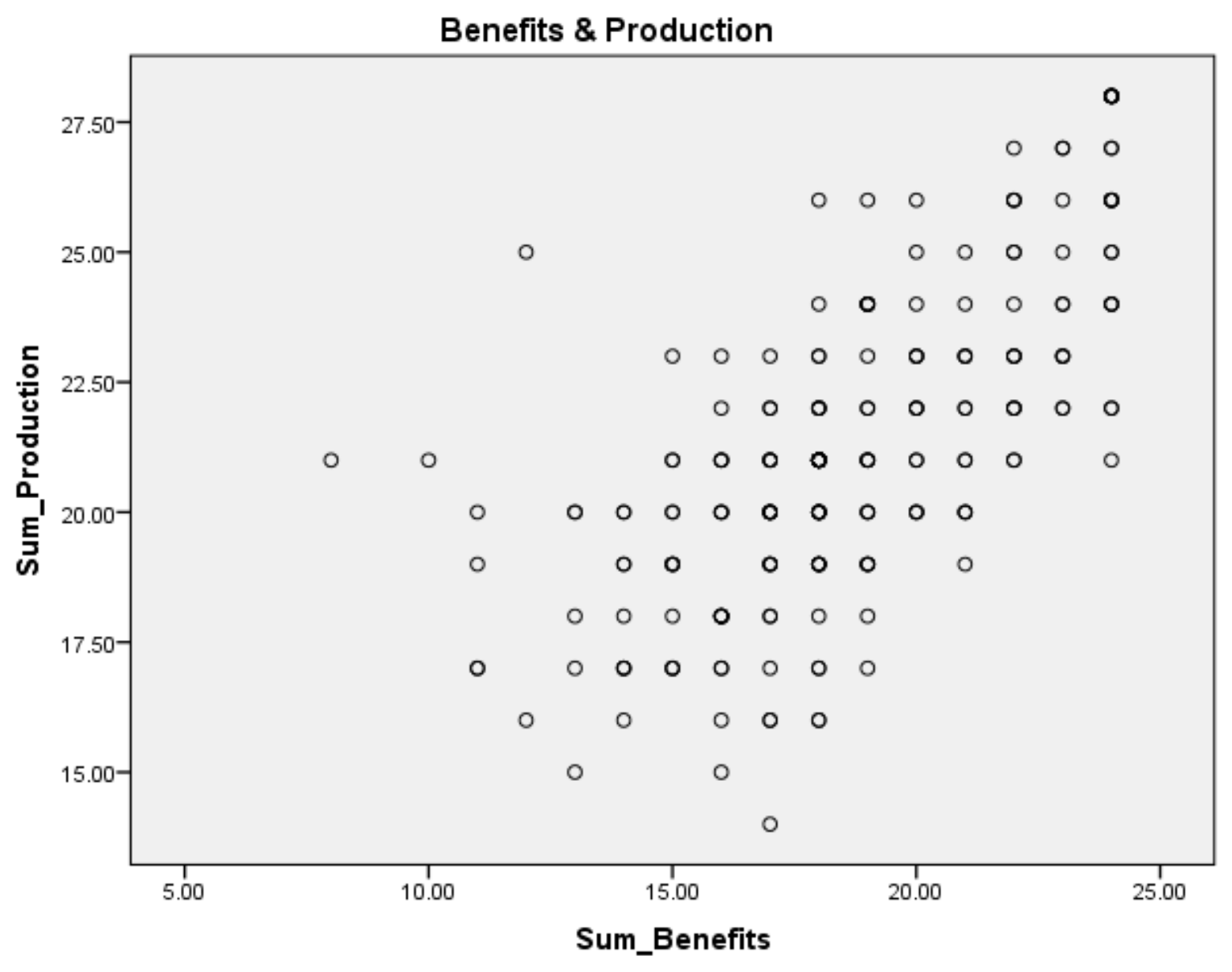

Figure 2. Scatter Plot of Positive Correlation

Figure 2 displays as teachers increased their agreement with the benefits of blended learning, they also reported a high level of the use of blended learning for student production.

\section{Discussion}

The results of the study have implications for future blended learning integration choices at the K-12 level. In completing the review of literature, there was limited focused research on K-12 blended learning, specifically by grade span groupings (Kassner, 2013). This research study focused on K-12 blended learning while disaggregating data into grade span groups: elementary, middle, and high school. The findings of this study indicated that there are aspects of blended learning that correlate to teachers' attitudes about blended learning practices by grade span groups rather than by $\mathrm{K}-12$ as a whole. It is possible that school districts can develop a more comprehensive plan for technology integration initiatives and professional development plans for blended learning by targeting different grade spans.

In addition, the results of this study indicate that as teachers increased their perception of the benefits of blended learning, teachers also increased their use of blended learning for instructional delivery and student production. Thus, teachers who recognize the potential benefits of blended learning for student achievement may be more likely to adopt technology integration and use it to enhance teaching and learning in the classroom. Schools may want to 
assess teacher attitude and attempt to positively impact teacher attitude to increase the use of blended learning.

\section{Conclusion}

Teachers' perceptions of blended learning differ by grade span grouping, which has implications for the manner in which teachers may be approached regarding their instructional strategies and delivery methods. Additional study is needed to determine the most effective use of blended learning. Additional study may be needed to delve into the reasons that elementary teachers have more positive perceptions of blended learning than middle and high school teachers. Elementary teachers could potentially see blended learning as a creative choice in instructional delivery, while middle and high school teachers could possibly see it as a mandated instructional delivery format for a course. Additional studies of these basic perceptions could provide insight into teacher attitude. This study adds to the limited body of knowledge related to blended learning in K-12 education by grade span groupings and provides direction for additional study.

\section{References}

Anderson, M., \& Perrin, A. (2016). 13\% of Americans don't use the internet. Who are they?. Pew Research Center. http://www.pewresearch.org/fact-tank/2016/09/07/some-americansdont-use-the-internet-who-are-they/

Christensen, C. M., Horn, M. B., \& Staker, H. (2013). Is K-12 blended learning disruptive? An introduction of the theory of hybrids. Clayton Christensen Institute. Retrieved from http://www.christenseninstitute.org

Guzer, B., \& Caner, H. (2014). The past, present, and future of blended learning: An in-depth analysis of literature. Procedia Social and Behavioral Sciences, $V . \quad 116$. https://doi.org/10.1016/j.sbspro.2014.01.992

Hillard, A. T. (2015). Global blended learning practices for teaching and learning, leadership, and professional development. Journal of International Education Research, 11(3), 179-188. https://doi.org/10.19030/jier.v11i3.9369

Jeffrey L. M., Milne, J., Suddaby, G., \& Higgins, A. (2014). Blended learning: How teachers balance the blend of online and classroom components. Journal of Information Technology Education: Research, 13, 121-140. https://doi.org/10.28945/1968

Kassner, L., \& Virginia Commonwealth University, M. (2013). A Review of Literature: Mix It up with Blended Learning in K-12 Schools. Retrieved from https://eric.ed.gov/?id=ED548381

Nadelson, L.S., Bennett, D., Gwilliam, E., Howlett, C., Oswalt, S., \& Sand, J. (2013). The intersection of preservice teachers' confidence, perceptions, and ideas for using instructional technology for teaching and learning. International Journal of Higher Education, 2(4). 77-90. https://doi.org/10.5430/ijhe.v2n4p77 


\section{Macrothink}

International Journal of Learning and Development

ISSN 2164-4063

2018, Vol. 8, No. 2

National Education Technology Plan. (2016). Future Ready Learning: Reimagining the Role of Technology in Education. Office of Educational Technology. http://tech.ed.gov

Oliver, K. M., \& Stallings, D. T. (2014). Preparing teachers for emerging blended learning environments. Journal of Technology and Teacher Education, 22(1), 57-81. Retrieved from https://www.learntechlib.org/p/112374/

Picciano, A. G., Dziuban, C. D., \& Graham, C. R. (2014). Blended learning research perspectives (Vol. 2) New York, NY: Routledge. https://doi.org/10.4324/9781315880310

Picciano, A.G., \& Seaman, J. (2009). Blending with purpose: The multimodal model. Journal of Asynchronous Learning Networks, 13(1). 7-18. https://eric.ed.gov/?id=EJ837540

Powell, A., Watson, J., Staley, P., Patrick, S., Horn, M., Fetzer, L., \& Verma, S. (2015). Blended learning: The evolution of online and face-to-face education from 2008-2015. Promising practices in blended and online learning series. International Association for K-12 online learning. Retrieved from http://files.eric.ed.gov/fulltext/ED560788.pdf

Stephens, T. (2016). 6 Common Misconceptions About Blended Learning. Getting Smart: http:/www.gettingsmart.com/2016/08/6-common-misconceptions-about-blended-learning/

Wang, Y., Han, X., \& Yang, J. (2015). Revisiting the blended learning literature: Using a complex adaptive systems framework. Educational Technology \& Society, 18(2), 380-393. Retrieved from http://www.jstor.org/stable/jeductechsoci.18.2.380

Whiteside, A. L. (2015). Introducing the social presence model to explore online and blended learning experiences. Online Learning, 19(2), 1-20. https://doi.org/10.24059/olj.v19i2.453

\section{Copyright Disclaimer}

Copyright for this article is retained by the author(s), with first publication rights granted to the journal.

This is an open-access article distributed under the terms and conditions of the Creative Commons Attribution license (http://creativecommons.org/licenses/by/4.0/). 